\title{
Should bank runs be prevented?
}

\author{
Margarita Samartín * \\ Departamento de Economia de la Empresa, Universidad Carlos III de Madrid, Calle Madrid 126, \\ 28903 Getafe, Spain
}

\begin{abstract}
This paper extends Diamond and Dybvig's model [J. Political Economy 91 (1983) 401] to a framework in which bank assets are risky, there is aggregate uncertainty about the demand for liquidity in the population and some individuals receive a signal about bank asset quality. Others must then try to deduce from observed withdrawals whether an unfavorable signal was received by this group or whether liquidity needs happen to be high. In this environment, both information-induced and pure panic runs will occur. However, banks can prevent them by designing the deposit contract appropriately. It is shown that in some cases it is optimal for the bank to prevent runs but there are situations where the bank run allocation may be welfare superior.
\end{abstract}

JEL classification $\mathrm{G} 21 ; \mathrm{G} 28$

Keywords Bank runs; Deposit contracts; Liquidation costs; Optimal risk sharing; Suspension of convertibility

\section{Introduction}

Banking crises have traditionally been an important source of public concern. Examples of financial crises in the history of the financial systems were the Great Depression (1929 1933) which had a significant impact on the banking system of the $\mathrm{US}^{1}$ or the more recent crises in emerging countries. ${ }^{2}$

\footnotetext{
${ }^{*}$ Tel +34916249647; fax +34916249608

E mail address samartin@emp uc3m es (M Samartm)

${ }^{1}$ From 1930 to 1933 the number of bank failures in the US averaged over 2000 per year (see Mishkin, 1995)

${ }^{2}$ Lindgren et al (1996) find that 73\% of the IMF's member countries suffered banking crises between 1980 and 1996
} 
Given the historical importance of banking panics and their current relevance it is important to understand why they occur and what policies should be implemented to deal with them. In this sense, the theoretical research on banking has focused on an alyzing the microeconomic nature of banks and their role in the economy. Diamond and Dybvig (1983), which formalized some of the ideas provided in Bryant (1980), made a significant contribution by modeling the demand for liquidity and the trans formation service provided by banks. They demonstrated that demand deposit con tracts, which enable the transformation of illiquid assets into more liquid liabilities, provide a rationale both for the existence of banks and for their vulnerability to runs. The optimal contract yields a higher level of consumption for those who withdraw early than the technological return. Bank runs, thus, take place when the idea of de posit withdrawals spills over economic agents (an essential point is that banks satisfy a sequential service constraint (see Wallace, 1988)). The model concludes that with no aggregate uncertainty, a suspension of convertibility policy can hinder the bank run equilibrium. Otherwise, a deposit insurance policy would be more effective. Di amond and Dybvig's model attracted severe criticisms (e.g., Gorton, 1988) for as suming that bank runs are random phenomena, and thus, uncorrelated with other economic variables. Gorton (1988), in an empirical study of bank runs in the US during the National Banking Era (1863 1913), found support for the notion that bank runs tended to occur after business cycle peaks.

Since the seminal work of Diamond and Dybvig, economists have used many variations of this model to explore banking issues. Bhattacharya and Gale (1987) consider a variation of the model with many intermediaries who face privately ob served liquidity shocks. They show the welfare gains from setting up an institution, such as a central bank, offering borrowing and lending opportunities at a subsidized rate. Jacklin and Bhattacharya (1988) introduce smooth preferences and a risky tech nology and show that the optimality of bank deposits compared to equities depends on the characteristics of the risky investment. Hellwig (1994) introduces interest rate risk and shows that as interest rates increase the optimal rate of deposits withdrawn in the first period should decrease and that of deposits that remain until the second one should increase. Champ et al. (1996) assume that the fraction of the population requiring liquidity is random and construct a monetary model where seasonal vari ations in the demand for liquidity play a critical role in generating banking panics. Hazlett (1997) makes the technology risky in order to explore the costs and benefits of deposit insurance. Allen and Gale (1998) also introduce a risky technology and show that under certain circumstances, bank runs can be first best efficient, as they allow efficient risk sharing among depositors and they allow banks to hold efficient portfolios. Alonso (1996) demonstrates using numerical examples that in the Jacklin and Bhattacharya framework contracts where runs occur may be better than con tracts that ensure runs do not occur because the former improve risk sharing. Fi nally, Lin (1996) models a continuum of types and Postlewaite and Vives (1987) extend the number of periods in the model.

The main objective of this paper is to cover one gap in this theory by extending the Diamond and Dybvig's framework to a situation in which there is both aggregate uncertainty about the demand for liquidity in the population and a risky technology. 
It is also assumed that the long term technology can be liquidated early at a cost. As in Chari and Jagannathan (1988) there is a signal extraction problem in which some individuals receive a signal about the bank's return, and others must infer from ob served withdrawals whether a negative signal was received by informed depositors or whether liquidity needs happen to be high. The difference with Chari and Jaganna than (1988) is that in this model individuals are risk averse and the ex ante optimal risk sharing contract is presented. ${ }^{3}$ As banks operate in a competitive environment, the optimal contract is the one that maximizes the expected utility of depositors. Also, banks are informed about the investment return and are fully rational, that is, they are aware depositors might receive interim information and they can foresee the consequences of different contract structures. In particular, two different con tracts are considered: The first contract ignores the impact of interim information at date 1 and as a result bank runs become a possibility. However, as self serving bank managers do not want to liquidate the investment (they want to keep their job) they will suspend convertibility whenever runs occur. It is then assumed that this suspension measure will only be effective when the bank is solvent. This means that suspension will be effective when the high value of the investment return is realized at date 2. In the case in which the low value of the investment return is realized at date 2 and it is lower than the liquidation value of the technology at date 1, then suspension cannot be sustained and the bank will be liquidated at date 1 . In the case of the sec ond contract, it is designed so that bank runs are always prevented.

The contribution of this paper is to show that bank runs are not always necessar ily bad in an ex ante welfare sense, that is, in some cases, banks will choose contracts where runs will occur with a positive probability. ${ }^{4}$ It is shown that if the probability of the low return occurring is below a critical value $\left(p^{*}\right)$, contracts that allow for runs would be welfare superior. This critical $p^{*}$ will depend on the level of risk aversion, the average return and the dispersion of the underlying technology. However, the liq uidation value of the long term technology is crucial in order to determine the supe riority of the demand deposit contract. If this liquidation value is considered to be even lower than the low return generated by the long term asset then a contract that prevents runs by penalizing early withdrawals (and therefore eliminating the with drawal incentive of individuals who do not need to consume early) dominates the previous contract. The reason is that a low liquidation value significantly increases the welfare costs of bank runs, and hence affects the optimality of the demand de posit contract.

The structure of the paper is as follows: The basic framework of the model is pre sented in Section 2. The risk sharing problem, subject to incentive compatibility, is presented in Section 3. In this case, the optimal allocation can be made contingent on the return on the risky asset and the withdrawal queue size, and is considered as the benchmark case. Section 4 considers the case in which the bank offers a typical

\footnotetext{
${ }^{3}$ Chari and Jagannathan's paper raised considerable criticisms due to the ambiguous role of banks or any other financial intermediary in the model, being assumed that individuals were risk neutral.

${ }^{4}$ This issue is also analyzed in Alonso (1996). However, she models a different environment that does not consider panic aspects and obtains different conditions under which bank runs should occur.
} 
demand deposit contract, that is not contingent on the return on the risky asset nor the liquidity needs. In Section 4.1 the bank designs the contract ignoring the impact of interim information and therefore bank runs will occur under certain conditions. Section 4.2 considers a quite different case in which the bank designs the deposit contract so that bank runs are always prevented. A welfare comparison of the two contracts, using numerical examples, is provided in Section 5. Finally, Section 6 con cludes the paper.

\section{The model}

The model can be summarized as follows: There is a three date period economy $(T=0,1,2)$ and one single commodity. There is one investment technology, that for each unit invested at $T=0$ generates a random return $\widetilde{R}$ at $T=2$. The value of this random return will be $R_{1}$ with probability $p$ and $R_{\mathrm{h}}$ with probability $1 p$. It is assumed that $0 \leqslant R_{1}<1<R_{\mathrm{h}}{ }^{5}$ and the average return $\left(\bar{R}=p R_{1}+\left(\begin{array}{ll}1 & p\end{array}\right) R_{\mathrm{h}}\right)$ is $>1$. If the production process is liquidated prematurely, then it will yield a liqui dation value of $L$. As this liquidation value is crucial for the results, two different cases will be considered: (a) The liquidation value is lower than the low value of the random return $\left(L<R_{1}\right)$ and (b) the liquidation value is between the low and the high value of the random return $\left(R_{\mathrm{l}}<L<1<R_{\mathrm{h}}\right)$.

On the household side of the economy, there is a continuum of ex ante identical agents that are endowed with one unit of the consumption good at $T=0$ and have no more endowment in the subsequent periods. They are subject at $T=1$ to a pri vately observed uninsurable risk of being of either of two types. Type 1 (or impa tient) agents derive only utility for consumption in period one and type 2 (or patient) agents derive only utility for consumption in period 2. In addition, type 2 agents can privately store the good from date 1 to date 2 . In order to obtain numer ical results, the following form for the utility function is assumed:

$$
U\left(c_{i}\right)=\frac{\left(c_{i}+1\right)^{1-\gamma}}{1 \gamma}, \quad i=1,2,
$$

where $\gamma$, the constant relative risk aversion coefficient, is assumed to be greater than one. ${ }^{6}$

Also, aggregate demand for liquidity is random, that is, the proportion of type 1 agents can be $t_{1}$ with probability $r_{1}$ or $t_{2}$ with probability $r_{2}\left(t_{1}+t_{2}=1\right.$ and $\left.t_{1}<t_{2}\right)$.

At $T=1$ a random fraction, $\tilde{\alpha}$, of type 2 individuals receives information about date 2 returns and it is assumed that this information is perfect, that is, they know with probability one the realization of the random return at $T=2$. This random

\footnotetext{
${ }^{5}$ The value of $R_{1}$ is sufficiently low, so that bad information about bank asset quality will lead always to a run.

${ }^{6}$ This function solves the problem that appears when the standard potential utility function is used and $\gamma>1$ : Zero consumption has an infinite negative value in terms of utility.
} 
Table 1

States of nature

\begin{tabular}{|c|c|c|c|c|}
\hline$\theta_{i} i$ & $\begin{array}{l}\text { State } \\
\tilde{t} \widetilde{\alpha} R\end{array}$ & $\begin{array}{l}\text { Prob. } \\
p\left(\theta_{i}\right)\end{array}$ & $\begin{array}{l}\text { Aggregate demand for liquidity } \\
\text { at } T=1\left(\widetilde{C T_{1}}\right)\end{array}$ & $\begin{array}{l}\widetilde{C T}_{1} \text { (Theorem } 3 \\
\text { satisfied) }\end{array}$ \\
\hline 1 & $t_{1} 0 \widetilde{R}$ & $r_{1}(1 \quad q)$ & $t_{1} c_{1}+\left(\begin{array}{ll}1 & t_{1}\end{array}\right) x_{\mathrm{U}}$ & $t_{1} c_{1}$ \\
\hline 2 & $t_{1} \alpha R_{\mathrm{h}}$ & $r_{1}(1 \quad p) q$ & $t_{1} c_{1}+\left(\begin{array}{ll}1 & t_{1}\end{array}\right)\left(\begin{array}{ll}1 & \alpha\end{array}\right) x_{\mathrm{U}}$ & $t_{1} c_{1}$ \\
\hline 3 & $t_{1} \propto R_{1}$ & $r_{1} p q$ & $t_{1} c_{1}+\left(\begin{array}{ll}1 & t_{1}\end{array}\right)\left[\alpha c_{1}+\left(\begin{array}{ll}1 & \alpha\end{array}\right) x_{\mathrm{U}}\right]$ & $c_{1}$ \\
\hline 4 & $t_{2} 0 \widetilde{R}$ & $r_{2}(1 \quad q)$ & $t_{2} c_{1}+\left(\begin{array}{ll}1 & t_{2}\end{array}\right) x_{\mathrm{U}}$ & $c_{1}$ \\
\hline 5 & $t_{2} \alpha R_{\mathrm{h}}$ & $r_{2}(1 \quad p) q$ & $t_{2} c_{1}+\left(\begin{array}{ll}1 & t_{2}\end{array}\right)(1 \quad \alpha) x_{\mathrm{U}}$ & $t_{2} c_{1}$ \\
\hline 6 & $t_{2} \alpha R_{1}$ & $r_{2} p q$ & $t_{2} c_{1}+\left(\begin{array}{ll}1 & t_{2}\end{array}\right)\left[\alpha c_{1}+\left(\begin{array}{ll}1 & \alpha\end{array}\right) x_{\mathrm{U}}\right]$ & $c_{1}$ \\
\hline
\end{tabular}

variable $\tilde{\alpha}$ can take a value $\alpha$ with probability $q$ and 0 with probability $1 q$. It is observed that in some states of nature, there will be no informed agents in the model.

As in Chari and Jagannathan (1988), the random proportion of type 1 agents is needed in order to create confusion between a large withdrawal queue size at the bank due to liquidity shocks, $t_{2}$ realized, or negative information shocks.

Finally, and in order for individuals to have a non trivial signaling extraction problem, the following parameter restriction is assumed (it will become clear later why this assumption is necessary):

$$
t_{2}=t_{1}+\alpha\left(1 \quad t_{1}\right) \text {. }
$$

The state of nature is described by the vector $\tilde{\theta}=(\tilde{t}, \tilde{\alpha}, \widetilde{R})$ that contains the three random variables that are independently distributed. Table 1 (columns 2 and 3) shows the different states of nature and its associated probabilities.

In the model, in line with the standard banking literature, it is assumed that banks have a comparative advantage in investing in the risky asset. At $T=0$ individuals deposit their funds in the bank in order to take advantage of this expertise. At $T=1$, when the preference and information shocks are realized, they will decide whether they wish to withdraw at $T=1$ or $T=2$. The banking sector is perfectly competitive, so banks offer risk sharing contracts that maximize depositors' ex ante expected utility, subject to a zero profit constraint. In this context, the incentive ef ficient allocation is identified with an optimal mechanism design problem in which the optimal allocation can be made contingent on the return on the risky asset $(\widetilde{R})$ and the liquidity shock $(\tilde{t})$ but not on depositors' types. This benchmark case will be compared with the risk sharing that is achieved in practice through a typical de mand deposit contract.

\section{The ex ante optimal risk sharing problem}

It is initially considered the ideal case where banks can write contracts in which the amount that can be withdrawn at each date is contingent on the random return $(\widetilde{R})$ and the withdrawal queue size $(\widetilde{t})$. The deposit contract will be represented by the functions $\tilde{c}_{1}, \tilde{c}_{2}$, which specify consumption for type 1 and type 2 consumers respec tively. 
The optimal incentive compatible risk sharing problem can be written as follows:

$$
\max _{\tilde{c}_{1}, \tilde{c}_{2}, \tilde{K}}\left\{E_{\tilde{R}, \tilde{t}}\left[\tilde{t} U\left(\tilde{c}_{1}\right)+\left(\begin{array}{ll}
1 & \tilde{t}
\end{array}\right) U\left(\tilde{c}_{2}\right)\right]\right\}
$$

s.t.

$$
\begin{aligned}
& \tilde{t}_{\tilde{c}_{1}} \leqslant \widetilde{K} L, \\
& \left(\begin{array}{ll}
1 & \tilde{t}
\end{array}\right) \tilde{c}_{2} \leqslant\left(\begin{array}{ll}
1 & \widetilde{K}
\end{array}\right) \widetilde{R} \quad \forall \widetilde{R}, \tilde{t}, \\
& \tilde{c}_{1} \leqslant \tilde{c}_{2},
\end{aligned}
$$

where $\tilde{c}_{1}$ represents consumption at time $T=1$ for the type 1 agent and $\tilde{c}_{2}$ con sumption at time $T=2$ for the type 2 agent and that will depend on $\widetilde{R}$ and $\tilde{t} . \widetilde{K}$ is the proportion of the long term investment that is liquidated at $T=1$, also contingent on the random return and the withdrawal queue size. The first two constraints represent resource balance constraints while the last one is the incentive compati bility constraint that guarantees that for each possible realization of $\widetilde{R}$ and $\tilde{t}$ the consumption of type 1 depositors should never exceed that of type 2 depositors, that is, the contract is designed so that individuals self select their type contract.

Equivalently, by eliminating $\widetilde{K}$ from the first and second resource constraints, the problem could be stated as follows:

$$
\max _{\tilde{c}_{1}, \tilde{c}_{2}}\left\{E_{\tilde{R}, \tilde{t}}\left[\tilde{t} U\left(\tilde{c}_{1}\right)+\left(\begin{array}{ll}
1 & \tilde{t}
\end{array}\right) U\left(\tilde{c}_{2}\right)\right]\right\}
$$

s.t.

$$
\begin{aligned}
& \tilde{t} \frac{\tilde{c}_{1}}{L}+(1 \quad \tilde{t}) \frac{\tilde{c}_{2}}{\widetilde{R}}=1 \quad \forall \widetilde{R}, \tilde{t}, \\
& \tilde{c}_{1} \leqslant \tilde{c}_{2} .
\end{aligned}
$$

The solution to the above problem is defined below.

Theorem 1. The solution $\left[\tilde{c}_{1}^{*}, \tilde{c}_{2}^{*}\right]$, to the optimal risk sharing problem is characterized by the following conditions:

If $\widetilde{R}<L$ :

$$
\tilde{c}_{1}^{*}=\tilde{c}_{2}^{*}=\frac{\widetilde{R} L}{\tilde{t} \widetilde{R}+\left(\begin{array}{ll}
1 & \tilde{t}
\end{array}\right) L} .
$$

If $\widetilde{R} \geqslant L$ :

$$
\tilde{c}_{1}^{*}=\frac{1+\frac{1-\tilde{t}}{R}\left[1 \quad\left(\frac{\tilde{R}}{L}\right)^{1 / \gamma}\right]}{\frac{(1-\tilde{t})}{L^{1 / \gamma}} \widetilde{R}^{(1-\gamma) / \gamma}+\frac{\tilde{t}}{L}} ; \quad \tilde{c}_{2}^{*}=\left(\frac{\widetilde{R}}{L}\right)^{1 / \gamma}\left(\tilde{c}_{1}+1\right)
$$

Proof. See Appendix A. 
Table 2

Numerical data

\begin{tabular}{|c|c|c|c|c|c|c|c|c|c|c|c|c|}
\hline$t_{1}$ & $t_{2}$ & $r_{1}$ & $r_{2}$ & $t$ & $R_{1}$ & $R_{\mathrm{h}}$ & $p$ & $\bar{R}$ & $\sigma^{2}$ & $\alpha$ & $q$ & $\gamma$ \\
\hline 0.50 & 0.70 & 0.90 & 0.10 & 0.52 & 0.21 & 1.57 & 0.20 & 1.30 & 0.30 & 0.40 & 0.99 & 4.0 \\
\hline
\end{tabular}

Case (a): $L=0.19$, case (b): $L=0.54$.

It can be observed that if the realized value of the long term asset is lower than its liquidation value at date $1(\widetilde{R}<L)$, then the optimal contract would involve giving both types of depositors the same consumption and the incentive constraint would be binding. Otherwise, the patient consumers would receive strictly more than the impatient ones and the incentive constraint would no longer bind.

For the parameter values shown in Table 2, in case (a), the optimal contract would be: $c_{1}^{*}=0.200, c_{2}^{*}=0.205$ for $t=t_{1}$ and $R=R_{1} ; c_{1}^{*}=0.260, c_{2}^{*}=1.109$ for $t=t_{1}$ and $R=R_{\mathrm{h}} ; c_{1}^{*}=0.199, c_{2}^{*}=0.206$ for $t=t_{2}$ and $R=R_{1}$. Finally, $c_{1}^{*}=0.228$, $c_{2}^{*}=1.057$ for $t=t_{2}$ and $R=R_{\mathrm{h}}$. The expected utility achieved is $U^{*}=0.122$.

Similarly, the optimal contract in case (b) would be: $c_{1}^{*}=c_{2}^{*}=0.297$ for $t=t_{1}$ and $R=R_{1} ; c_{1}^{*}=0.673, c_{2}^{*}=1.186$ for $t=t_{1}$ and $R=R_{\mathrm{h}} ; c_{1}^{*}=c_{2}^{*}=0.362$ for $t=t_{2}$ and $R=R_{1}$. Finally, $c_{1}^{*}=0.609, c_{2}^{*}=1.103$ for $t=t_{2}$ and $R=R_{\mathrm{h}}$. The expected utility achieved is $U^{*}=0.073$.

\section{The demand deposit contract}

The optimal risk sharing problem of the preceding section serves as a benchmark for the risk sharing that can be achieved in practice with the type of contracts that banks are restricted to use. Let a demand deposit contract be defined as a contract that requires an initial investment at $T=0$ with the intermediary in exchange for the right to withdraw per unit of initial investment (at the discretion of depositor and conditional on the bank's solvency) either $c_{1}$ units in period 1 or $\tilde{c}_{2}$ units in period 2. The second period random payment will depend on the withdrawal queue size $\tilde{t}$ and the random return $\widetilde{R},{ }^{7}$ so that $c_{2 \mathrm{~h}}^{t_{1}}$ will represent consumption at date 2 if the high return is realized and if the proportion of type 1 consumers is $t_{1}$. Similarly, $c_{21}^{t_{1}}$ represents consumption at date 2 if the low return is realized and if the proportion of type 1 consumers is $t_{1}$. The unknowns $c_{2 \mathrm{~h}}^{t_{2}}$ and $c_{2 \mathrm{l}}^{t_{2}}$ are defined in a similar way.

As mentioned in the introduction, competition forces the bank to offer a deposit contract that maximizes the expected utility of depositors. Also, banks are informed of the investment return in the interim period and are fully rational, that is, they are aware depositors might receive interim information and they can foresee the conse quences of different contract structures. In particular, two different contracts are con sidered: In the first subsection the contract ignores the impact of interim information

\footnotetext{
${ }^{7}$ This uncertain second period return reflects the fact that having invested in a risky asset the bank may not be able to make its promised payments at date 2 .
} 
at $T=1$ and therefore bank runs will occur under certain conditions. In the second subsection the contract is designed so that runs do not occur.

\subsection{The demand deposit contract with runs}

The optimal contract choice for a deposit contract, in the absence of interim in formation can be obtained as a solution to the following problem:

$$
\begin{aligned}
\max _{\substack{c_{1}, c_{2 \mathrm{~h}}^{t_{1}}, c_{21}^{t_{21}}, c_{2 \mathrm{~h}}, c_{21}^{t_{21}}\\
}} & r_{1}\left(t_{1} U\left(c_{1}\right)+\left(\begin{array}{ll}
1 & t_{1}
\end{array}\right)\left[\left(\begin{array}{ll}
1 & p
\end{array}\right) U\left(c_{2 \mathrm{~h}}^{t_{1}}\right)+p U\left(c_{21}^{t_{1}}\right)\right]\right) \\
& \left.+r_{2}\left(t_{2} U\left(c_{1}\right)+\left(\begin{array}{ll}
1 & t_{2}
\end{array}\right)\left[\left(\begin{array}{ll}
1 & p
\end{array}\right) U\left(c_{2 \mathrm{~h}}^{t_{2}}\right)+p U\left(c_{21}^{t_{2}}\right)\right]\right)\right\}
\end{aligned}
$$

s.t.

$$
\begin{aligned}
& t_{1} \frac{c_{1}}{L}+\left(1 \quad t_{1}\right) \frac{c_{2 \mathrm{~h}}^{t_{1}}}{R_{\mathrm{h}}}=1 ; \quad t_{1} \frac{c_{1}}{L}+\left(1 \quad t_{1}\right) \frac{c_{21}^{t_{1}}}{R_{1}}=1 \\
& t_{2} \frac{c_{1}}{L}+\left(\begin{array}{ll}
1 & t_{2}
\end{array}\right) \frac{c_{2 \mathrm{~h}}^{t_{2}}}{R_{\mathrm{h}}}=1 ; \quad t_{2} \frac{c_{1}}{L}+\left(\begin{array}{ll}
1 & t_{2}
\end{array}\right) \frac{c_{21}^{t_{2}}}{R_{1}}=1,
\end{aligned}
$$

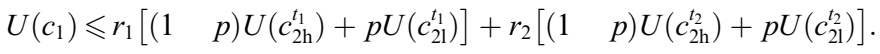

The first four constraints are the corresponding resource constraints and the last one is the incentive compatibility constraint, which is expressed in expected terms (using the ex ante probabilities) given that the contract ignores the impact of interim in formation at date 1 .

The solution to this problem is given by the following theorem:

Theorem 2. The solution $c_{1}^{*}, c_{2 \mathrm{~h}}^{t_{1} *}, c_{2 \mathrm{~h}}^{t_{2} *}, c_{21}^{t_{1} *}, c_{21}^{t_{2} *}$ to the demand deposit contract is characterized by the following conditions:

$$
c_{2 \mathrm{~h}}^{t_{1} *}=\frac{\left(1 \frac{t_{1}}{L} c_{1}^{*}\right) R_{\mathrm{h}}}{1 \quad t_{1}} ; \quad c_{21}^{t_{1} *}=c_{2 \mathrm{~h}}^{t_{1} *} \frac{R_{1}}{R_{\mathrm{h}}} ; \quad c_{2 \mathrm{~h}}^{t_{2} *}=\frac{\left(\begin{array}{ll}
1 & \frac{t_{2}}{L} c_{1}^{*}
\end{array}\right) R_{\mathrm{h}}}{1 \quad t_{2}} ; \quad c_{21}^{t_{2} *}=c_{2 \mathrm{~h}}^{t_{2} *} \frac{R_{1}}{R_{\mathrm{h}}}
$$

and $c_{1}^{*}$ is the solution to the following non linear equation:

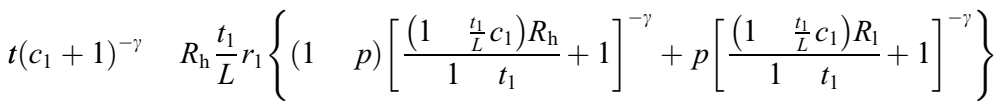

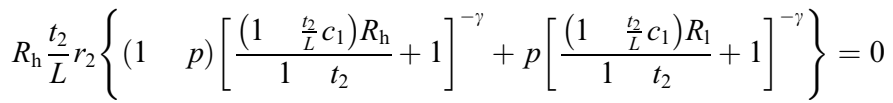

where $t=r_{1} t_{1}+r_{2} t_{2}$

if the incentive compatibility constraint is not binding. Otherwise, the unknown $c_{1}^{*}$ must satisfy the incentive compatibility constraint.

Proof. See Appendix B. 
Suppose now that at $T=0$, when individuals deposit their unit of endowment in the bank, the above contract is offered. At $T=1$ or the interim stage, the preference and information shocks are realized, and so every individual learns his or her type, that is, they know whether they are impatient consumers, who need to consume in the interim period or patient agents who prefer to consume at date 2. Also, a fraction of type 2 or patient consumers will receive a signal that reveals with perfect accuracy the return of the long term asset at $T=2$. Given these shocks, individuals will decide on the amount they wish to withdraw at each date. The withdrawal decision of type 1 individuals is trivial. As these agents face liquidity needs at date 1, they will always select their own contract or withdrawal stream $\left(c_{1}^{*}\right)$. Similarly, informed type 2 indi viduals will choose to withdraw their funds from the bank, that is, to select the type 1 contract, if they receive a negative information shock. They would maintain their funds if they receive a positive one. The demand for liquidity of informed agents, conditional on each state of nature, will be denoted by $\tilde{x}_{I}$. Finally, there are unin formed type 2 agents, who will try to figure out when a negative signal has occurred by looking at the size of early withdrawals from the bank. However, this size can be large enough due to both a negative information shock or to a liquidity shock (those states of nature in which the highest proportion of type 1 agents is realized, i.e $t=t_{2}$ ). As a result, equilibria have the property that massive bank withdrawals by the un informed depositors are sometimes due to an incorrect inference that the bank's as sets will yield a low return. Similarly to the informed agents case, the demand for liquidity for uninformed agents will be denoted by $\tilde{x}_{\mathrm{U}}$. In the following lines, we will characterize the optimal withdrawal decision of the uninformed agents for each state of nature. Let $\widetilde{C T_{1}}$ represent the withdrawal queue size or the level of aggregate de mand for liquidity at date 1 for each state of nature, that is,

$$
\widetilde{C T}_{1}=\tilde{t} c_{1}^{*}+\left(\begin{array}{ll}
1 & \tilde{t}
\end{array}\right)\left[\begin{array}{c}
\tilde{\alpha} \tilde{x}_{\mathrm{I}}+\left(\begin{array}{ll}
1 & \tilde{\alpha}
\end{array}\right) \tilde{x}_{\mathrm{U}}
\end{array}\right]
$$

where $\tilde{x}_{I}, \tilde{x}_{U}$ represent demand for liquidity at date 1 for informed and uninformed type 2 agents respectively. ${ }^{8}$ The values of $\widetilde{C T}_{1}$ are shown in Table 1 (column 4 ).

We assume that the information partitions of the uninformed type 2 in the con jectured equilibrium are as follows:

$C T_{1}=t_{1} c_{1}, \quad$ which implies states $\theta=1,2$.

As individuals cannot distinguish between the two states they would assign a con ditional probability $\pi_{1_{(1,2)}}=\left(\begin{array}{ll}1 & p\end{array}\right) r_{1} /\left(r_{1}\left(\begin{array}{ll}1 & q\end{array}\right)+r_{1}\left(\begin{array}{ll}1 & p\end{array}\right) q\right)$ to receiving the high est second period consumption (i.e when $\widetilde{R}=R_{\mathrm{h}}$ occurs) and $\pi_{2_{(1,2)}}=p r_{1}\left(\begin{array}{ll}1 & q\end{array}\right) /$ $\left.\left(\begin{array}{ll}r_{1}\left(\begin{array}{ll}1 & q\end{array}\right)+r_{1}(1 & p\end{array}\right) q\right)$ to receiving the lowest second period one (i.e. when $\widetilde{R}=$ $R_{1}$ occurs).

$C T_{1}=c_{1}, \quad$ which implies states $\theta=3,4$ and 6.

Similarly, as individuals cannot distinguish among those states they would as sign a conditional probability $\pi_{1_{(3,4,6)}}=\left(\begin{array}{lll}1 & p\end{array}\right) r_{2}\left(\begin{array}{ll}1 & q\end{array}\right) /\left(r_{2}\left[\left(\begin{array}{ll}1 & q\end{array}\right)+p q\right]+r_{1} p q\right)$ to

\footnotetext{
${ }^{8}$ Note that the demand for liquidity of informed agents is $x_{\mathrm{I}}=0$ in states 2 and 5 and $x_{\mathrm{I}}=c_{1}$ in states 3 and 6
} 
receiving the highest second period consumption and $\left.\pi_{2_{(3,4,6)}}=p\left[\begin{array}{ll}q+r_{2}(1 & q\end{array}\right)\right] /$ $\left(r_{2}\left[\left(\begin{array}{ll}1 & q\end{array}\right)+p q\right]+r_{1} p q\right)$ to receiving the lowest second period one.

$C T_{1}=t_{2} c_{1}, \quad$ which implies state $\theta=5$.

Given the above information partitions, we will characterize the optimal with drawal decision of uninformed agents for each state of nature.

(i) States 1 and 2: It is optimal for the uninformed agent not to withdraw in states 1 and 2 if the following condition holds:

$$
\frac{\left(c_{1}^{*}+1\right)^{1-\gamma}}{1 \gamma} \leqslant \pi_{1_{(1,2)}} \frac{\left(c_{2 \mathrm{~h}}^{t_{1} *}+1\right)^{1-\gamma}}{1 \gamma}+\pi_{2_{(1,2)}} \frac{\left(c_{2 \mathrm{~h}}^{t_{1} * \frac{R_{1}}{R_{\mathrm{h}}}}+1\right)^{1-\gamma}}{1 \gamma} .
$$

The left side of Eq. (15) is the utility that the uninformed depositor obtains by withdrawing in states 1 and 2 and the right side is the expected utility of not with drawing in those states.

(ii) States 3, 4 and 6: It is optimal for the uninformed agent to withdraw in states 3,4 and 6 if the following condition holds:

$$
\begin{aligned}
& \frac{\left(c_{1}^{*}+1\right)^{1-\gamma}}{1 \gamma} \geqslant r_{1}\left[\pi_{1_{(3,4,6)}} \frac{\left(c_{2 \mathrm{~h}}^{t_{1} *}+1\right)^{1-\gamma}}{1 \gamma}+\pi_{2_{(3,4,6)}} \frac{\left(c_{2 \mathrm{~h}}^{t_{1} * \frac{R_{1}}{R_{\mathrm{h}}}}+1\right)^{1-\gamma}}{1 \gamma}\right] \\
& +r_{2}\left[\pi_{1_{(3,4,6)}} \frac{\left(c_{2 \mathrm{~h}}^{t_{2} *}+1\right)^{1-\gamma}}{1 \gamma}+\pi_{2(3,4,6)} \frac{\left(c_{2 \mathrm{~h}}^{t_{2} * \frac{R_{1}}{R_{\mathrm{h}}}}+1\right)^{1-\gamma}}{1 \gamma}\right] .
\end{aligned}
$$

Similarly, the left side of Eq. (16) is the utility that an uninformed depositor obtains by withdrawing in states 3,4 and 6 and the right side is the expected utility of not withdrawing in those states.

(iii) State 5: It is optimal not to withdraw in state 5 if the following condition holds:

$$
\frac{\left(c_{1}^{*}+1\right)^{1-\gamma}}{1 \gamma} \leqslant \frac{\left(c_{2 \mathrm{~h}}^{t_{2}}+1\right)^{1-\gamma}}{1 \gamma} .
$$

Finally, the left side of Eq. (17) is the utility that an uninformed depositor obtains by withdrawing and the right side is the utility of not withdrawing in state 5 .

Conditions for both information induced and pure panic runs are given by the following theorem.

Theorem 3. Assuming the condition given by Eq. (2) and that Eqs. (15) (17) are sat isfied, then there exists in the model an equilibrium with bank runs.

Theorem 3 implies bank runs occur as a unique equilibrium in states 3,4 and 6 . In states 3 and 6 there exist information induced runs as there is a negative information shock received by the informed individuals which induces the uninformed to with 
draw as well. However in state 4 there is a pure panic run as there is no adverse in formation held by any agent in this state. In this case the uninformed have mistak enly withdrawn their funds from the bank.

As mentioned in the introduction, whenever there are runs, self serving bank managers will suspend convertibility. It is assumed that the suspension level will be the highest proportion of type 1 depositors. The bank distributes the type 1 con tract until a fraction equal to the highest proportion of type 1 consumers $\left(t_{2}\right)$ has withdrawn, after that, the bank will only give out all the available second period con sumption. Clearly, there is a gain in states where there is no information held by any agent (state 4) and a loss when (i) there is bad information (states 3 and 6) and (ii) some type 1 depositors (who face liquidity needs) are prevented from withdrawing in this rationing rule, as it is assumed that agents arrive randomly at the bank and are then treated on a first come first served basis. Let $\tilde{\beta}^{9}$ be the random proportion of agents of each type that are being rationed by the bank, that is, receive no payment at date 1 . The $1 \quad \beta$ remaining agents are those that are able to receive the promised payment $c_{1}^{*}$ at date 1 . This means that total consumption at date 1 should be equal to the suspension level, that is $\left(\begin{array}{ll}1 & \tilde{\beta}\end{array}\right) \widetilde{C T_{1}}=t_{2} C_{1}^{*}$ or equivalently, $\tilde{\beta}=\left(\begin{array}{ll}\widetilde{C T_{1}} & t_{2} C_{1}^{*}\end{array}\right) / \widetilde{C T_{1}}$ if there are runs and otherwise $\tilde{\beta}=0$.

However, this suspension measure is only effective when the bank is solvent. This assumption is based on Park (1991). ${ }^{10}$ This implies that the bank is liquidated in the bad states, in the case in which the liquidation value of the long term technology is higher than the low return $\left(R_{1}<L<R_{\mathrm{h}}\right)$. In these states all agents claim the type 1 contract but only a fraction $f_{\max }$ of them will be able to receive first period consump tion. This means that in these states the first period resource constraint would be come

$$
f_{\max } c_{1}^{*}=L
$$

where the long term technology has been totally liquidated in period one, that is, $K=1$.

In the second case, in which the liquidation value at date 1 is lower than the low return $\left(L<R_{1}\right)$ suspension would be effective, even in the bad states. The ex ante ex pected utility with suspension of convertibility is derived in Appendix B.1.

For the parameter values considered in Table 2, in case (a), the demand deposit contract would be: $c_{1}^{*}=0.243, c_{2 \mathrm{~h}}^{t_{1} *}=1.235, c_{21}^{t_{1} *}=0.160, c_{2 \mathrm{~h}}^{t_{2} *}=0.782$ and $c_{21}^{t_{2} *}=$ 0.102 . The expected utility with suspension $\left(U_{\text {runs }}\right)$, when liquidation takes place in the bad states, is 0.151 .

Similarly, in case (b), the demand deposit contract would be $c_{1}^{*}=0.638, c_{2 \mathrm{~h}}^{t_{1} *}=$ $1.288, c_{21}^{t_{1} *}=0.167, c_{2 \mathrm{~h}}^{t_{2} *}=0.909$ and $c_{21}^{t_{2} *}=0.118$. The expected utility with suspension $\left(U_{\text {runs }}\right)$ is 0.088 .

\footnotetext{
${ }^{9}$ Equivalently, we could have considered $\tilde{\beta}_{1}, \tilde{\beta}_{\mathrm{I}}, \tilde{\beta}_{\mathrm{U}}$ random proportions of agents of each type. However, this would have added an additional complication into the analysis, without changing the essence of the result.

${ }^{10}$ This paper shows that suspension of convertibility was a means to prove the bank's solvency. Historically, suspension was only for a brief period and insolvent banks were liquidated.
} 


\subsection{The demand deposit contract without runs}

It is now considered a contract which makes sure bank runs will not occur, as a result of the negative information shock. This contract solves the same problem as the one in the previous subsection with one exception: There are two additional in centive constraints that have to be added. These constraints describe when it is ratio nal for an informed agent to truthfully reveal his type:

$$
\begin{aligned}
& U\left(c_{1}\right) \leqslant r_{1} U\left(c_{21}^{t_{1}}\right)+r_{2} U\left(c_{21}^{t_{2}}\right), \\
& U\left(c_{1}\right) \leqslant r_{1} U\left(c_{2 \mathrm{~h}}^{t_{1}}\right)+r_{2} U\left(c_{2 \mathrm{~h}}^{t_{2}}\right) .
\end{aligned}
$$

However, if the contract satisfies Eq. (19a) it will also satisfy Eq. (19b) (and Eq. (11)). The optimal contract in this case is obtained by maximizing the ex ante ex pected utility given by Eq. (9) subject to constraints (10) and (19a). The effect of imposing this last constraint is to penalize first period consumption up to the point the withdrawal incentive of individuals who do not need to consume early is elimi nated.

The solution to this problem is defined by the following theorem:

Theorem 4. The solution $c_{1}^{*}, c_{2 \mathrm{~h}}^{t_{1} *}, c_{2 \mathrm{~h}}^{t_{2} *}$ to the demand deposit contract is characterized by the following conditions:

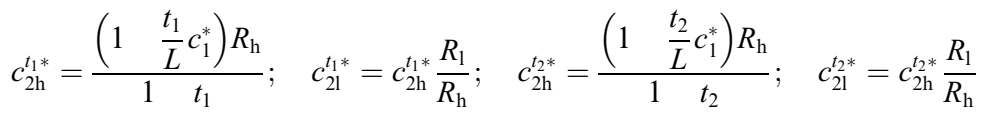

and $c_{1}^{*}$ is the solution to the following non linear equation:

$$
\left(c_{1}+1\right)^{1-\gamma}\left\{r_{1}\left[\frac{\left(1 \frac{t_{1}}{L} c_{1}\right) R_{1}}{1 t_{1}}+1\right]^{1-\gamma}+r_{2}\left[\frac{\left(1 \frac{t_{2}}{L} c_{1}\right) R_{1}}{1 \frac{t_{2}}{t_{2}}+1}\right]^{1-\gamma}\right\}=0 .
$$

For the parameter values considered in Table 2, in case (a), the demand deposit contract would yield: $c_{1}^{*}=0.202, \quad c_{2 \mathrm{~h}}^{t_{1} *}=1.557, \quad c_{21}^{t_{1} *}=0.202, \quad c_{2 \mathrm{~h}}^{t_{*} *}=1.535$ and $c_{21}^{t_{2} *}=0.200$. The expected utility achieved ( $\left.U_{\text {no-runs }}\right)$ is 0.125 . Similarly, in case (b), the demand deposit contract would be: $c_{1}^{*}=0.304, c_{2 \mathrm{~h}}^{t_{1} *}=2.261, c_{21}^{t_{1} *}=0.294$, $c_{2 \mathrm{~h}}^{t_{2} *}=3.178$ and $c_{21}^{t_{2} *}=0.413$. The expected utility achieved $\left(U_{\text {no-runs }}\right)$ is 0.096 .

\section{Welfare comparisons: Numerical examples}

The previous sections have characterized the level of risk sharing that is achieved when (i) the optimal contract can be conditioned on the random return and the liquid ity shock (second best allocation) and (ii) the bank is restricted to use a demand de 
posit contract, as observed in practice. It is first considered a contract which allows for the possibility of runs, and secondly, the contract is designed so that runs do not occur.

The aim of this section is to compare, using numerical examples, the above men tioned risk sharing contracts. In these examples, the allocations are determined as described in the previous sections.

Let $t=0.52, r_{1}=0.90, r_{2}=0.10, \alpha=0.40$ and $q=0.99$. As it can be observed, it has been assumed that the lowest proportion of type 1 agents $\left(t_{1}\right)$ is realized with a high probability $\left(r_{1}=0.90\right)$. The motivation for this assumption is to create confu sion between a large withdrawal queue size at the bank, due to a high liquidity shock $\left(t_{2}\right.$ realized), or a negative information shock. Also, in all the numerical examples Theorem 3 is satisfied, that is, bank runs occur as a unique equilibrium. ${ }^{11}$

Given these parameters, Figs. 14 display the difference between (i) the expected utility achieved with a demand deposit contract that allows for runs and the expected utility of the second best allocation and (ii) the expected utility with a demand de posit contract that avoids runs and the expected utility of the second best outcome, both as a function of the relative risk aversion coefficient $(\gamma)$. The figures differ in the probability of the low return occurring $(p)$ and in the liquidation value of the long term technology $(L)$.

Figs. 1 and 2 illustrate the case in which the liquidation value of the long term technology is assumed to be below the bad return $\left(R_{1}\right)$ and the probability of this low return occurring is 0.20 and 0.40 respectively. A common feature to these two figures is that a contract that prevents runs attains greater risk sharing than one that allows for runs, also the former contract approaches the second best outcome. Given that the long term technology is liquidated only at a loss, this increases significantly the welfare costs of bank runs and therefore it is always better to prevent runs, al though this implies penalizing first period consumption up to the point the with drawal incentives of individuals who do not need to consume early is eliminated.

Figs. 3 and 4 illustrate the case in which the liquidation value of the long term technology is assumed to be between the low and the high return and the probability of the low return occurring is 0.20 and 0.40 respectively. The results differ from the previous cases, as now the superiority between the two contracts will depend on the probability of the low return. In the case of Fig. $3(p=0.20)$, contracts that allow for runs achieve greater risk sharing that contracts that prevent runs. As in Alonso (1996) this is because in order to change the deposit contract so that investors have an incentive not to run, the depositors' payoffs have to be altered in all states of na ture, hence, a significant loss is incurred with high probability and the gain is only realized with low probability. This loss is greater in this case than the one incurred by liquidation. However, in the case of Fig. $4(p=0.40)$, contracts that allow for runs would be preferred only for very high levels of risk aversion. The reason is that now, the loss of preventing bank runs by altering the deposit payoffs in all states of

\footnotetext{
${ }^{11}$ It should be mentioned that we have focused on one possible equilibrium in order to explore the welfare properties of the demand deposit contract in this framework. However, there may exist other equilibria in the model.
} 


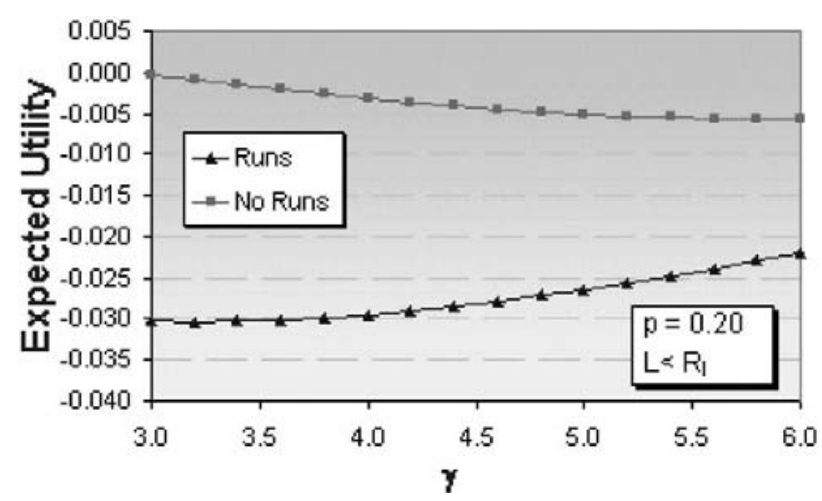

Fig. 1. Expected utility with runs minus second best and expected utility with no runs minus second best as a function of $\gamma$, and assuming the probability of the low return is $p=0.20$ and case (a).

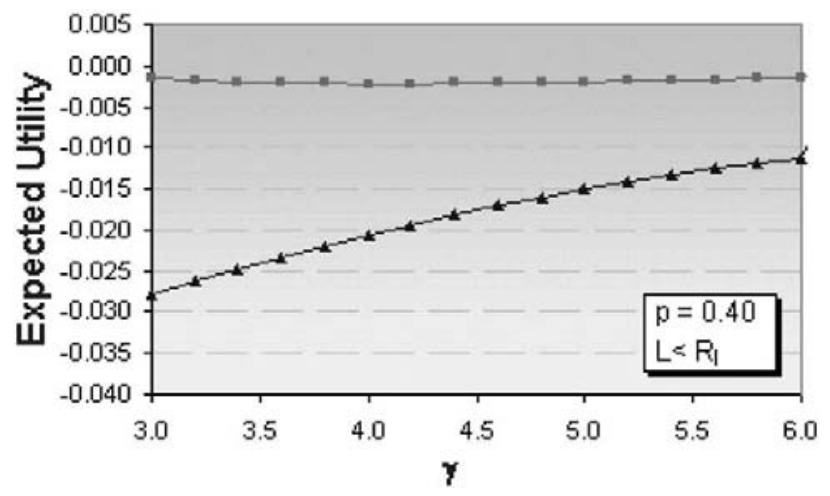

Fig. 2. Expected utility with runs minus second best and expected utility with no runs minus second best as a function of $\gamma$, and assuming the probability of the low return is $p=0.40$ and case (a).

nature is incurred with lower probability and is less than the one incurred by liqui dation. ${ }^{12}$

Fig. 5 summarizes these results (for the more interesting case in which the liqui dation value is between the low and high return). It gives the critical probability $\left(p^{*}\right)$ below which contracts that allow for runs would be welfare superior, as a func tion of the relative risk aversion coefficient and assuming different values in the dis

\footnotetext{
${ }^{12}$ As mentioned in the introduction this issue is also analyzed in a recent paper by Alonso (1996). In her case she finds that contracts with runs are beneficial if the probability of a bad signal reaching a subset of depositors is sufficiently low.
} 


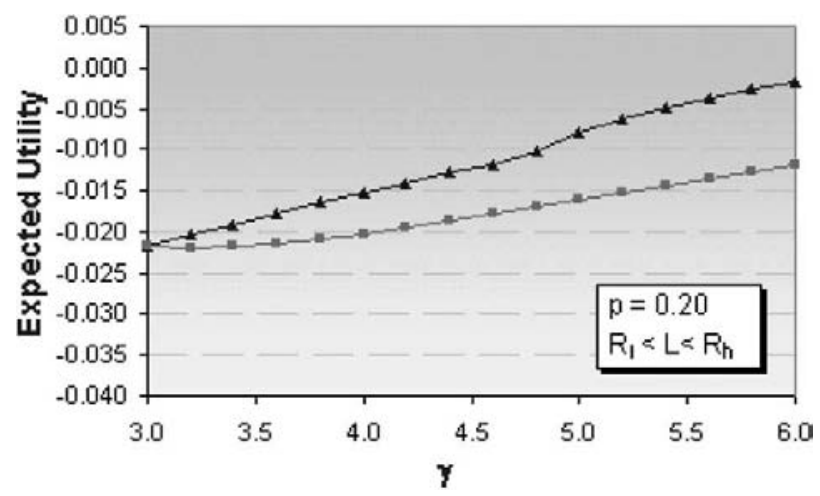

Fig. 3. Expected utility with runs minus second best and expected utility with no runs minus second best as a function of $\gamma$, and assuming the probability of the low return is $p=0.20$ and case (b).

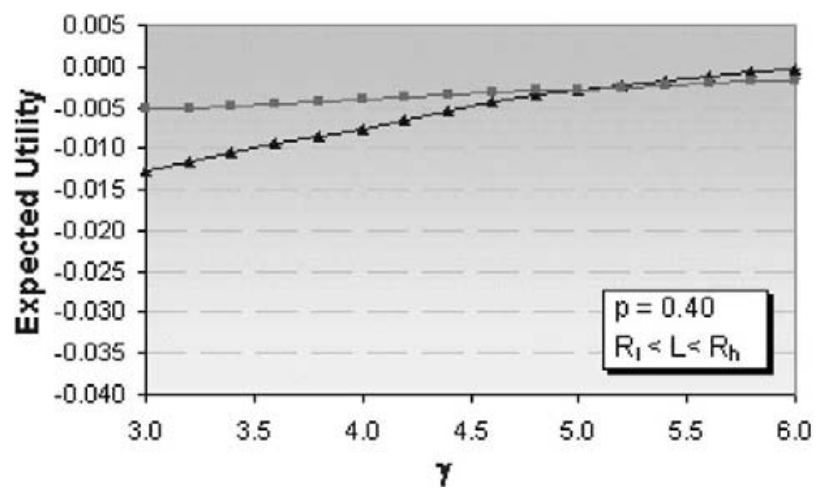

Fig. 4. Expected utility with runs minus second best and expected utility with no runs minus second best as a function of $\gamma$, and assuming the probability of the low return is $p=0.40$ and case (b).

persion and average return of the underlying technology. It is observed that this crit ical $p^{*}$ is always decreasing in the average return and increasing in the dispersion of the random asset, measured by the variance of the asset's return and is also increas ing in the level of risk aversion. The effect of risk aversion seems more important the higher is the dispersion in the long term return and the lower its average return. These results imply that the region below which it becomes optimal to allow runs in creases as risk aversion or the dispersion of the long return increase or if the average return decreases. It could also be shown that the critical probability is increasing in the liquidation value of the long term asset.

Finally, it should be mentioned that these results hold in the case in which indi viduals have CRRA $>1$. The extension of the above results to a more general utility 


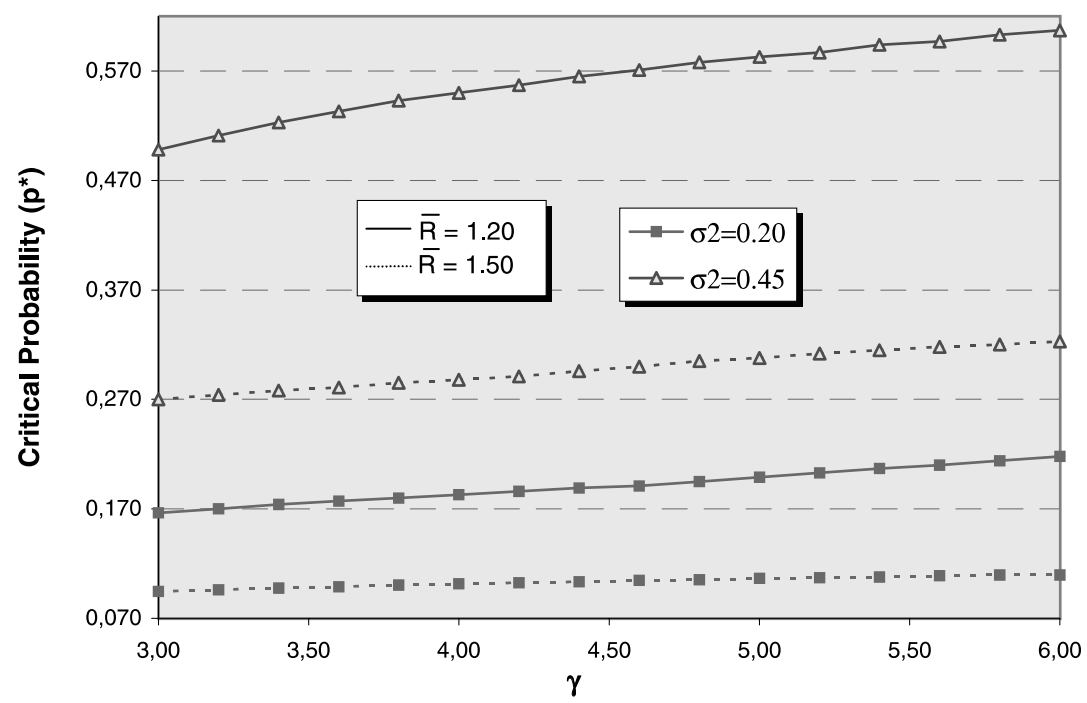

Fig. 5. Critical probability below which contracts that allow for runs are welfare superior, as a function of the relative risk aversion coefficient, and assuming different values in the dispersion and average return.

function would be a task for future research. However, it should be added that the specific form of the utility function (the fact that individuals have corner preferences) is not essential for the above conclusions, that is, the above results would remain valid if a more general preference structure was considered (where individuals derive utility for consumption in both periods of their lives).

\section{Concluding remarks}

This paper combines features of Diamond and Dybvig (1983) and Chari and Ja gannathan (1988) models to explore in depth the optimality of a demand deposit contract. We consider a framework in which bank assets are risky, there is aggregate uncertainty about the demand for liquidity in the population and some individuals receive a signal about bank asset quality. Others must then try to infer from observed withdrawals whether an unfavorable signal was received by this group or whether liquidity needs happen to be high. In this environment information induced and pure panic runs will occur. In the model there are two types of social costs associated with bank runs: One is the cost of liquidating the long term investment and the other is the fact runs occur in some states although no one has adverse information.

In this context, the incentive efficient allocation is identified with an optimal mechanism design problem in which the optimal allocation can be made contingent on the return on the risky asset $(\widetilde{R})$ and the liquidity shock $(\tilde{t})$ but not on depositors' 
types. If the bank could implement this allocation, there would be no bank runs. This benchmark case is then compared with the risk sharing that is achieved in practice through a typical demand deposit contract. It is assumed that banks are fully ratio nal, that is, they are aware depositors might receive interim information and they can foresee the consequences of different contract structures. In particular, two different contracts are considered: One contract allows for the possibility of runs while the other one is designed so that bank runs are always prevented.

In order to analyze the welfare properties of the two contracts, some numerical examples have been provided. The liquidation value of the long term asset and the probability of the low outcome are crucial in order to determine the superiority be tween the two contracts. Two different cases are therefore considered: In the first case the liquidation value of the long term asset is assumed to be lower than the low re turn. In this case a contract that prevents runs is always welfare superior and achieves the second best outcome. The reason is that a low liquidation value signif icantly increases the welfare costs of bank runs and as a result it is better to prevent runs although this implies penalizing first period consumption up to the point the withdrawal incentives of depositors who do not need to consume early is eliminated. In the second case the liquidation value is assumed to be between the low and high return. The superiority between the two contracts depends on the probability of the low return. It is shown that if this probability is below a critical value $\left(p^{*}\right)$, contracts that allow for runs attain greater risk sharing than contracts that prevent runs. As in Alonso (1996), the reason is that in order to change the deposit contract so that in vestors have an incentive not to run, the depositors' payoffs have to be altered in all states of nature, hence, a significant loss is incurred with high probability, and the gain is only realized with low probability. This loss is now higher than the welfare costs associated with bank runs. This critical probability depends on the exogenous parameters of the model: It is increasing in the level of risk aversion, in the liquida tion value and in the dispersion of the long term asset. On the contrary, it is decreas ing in its average return.

\section{Acknowledgements}

This research is partially funded by the Spanish Ministry of Education and Cul ture, projects: PB97 0089, DGES and SEC 2001 1169. The author owes special thanks to Sudipto Bhattacharya, Sandro Brusco and two anonymous referees for their very helpful comments in earlier versions of this paper. The advice of Giorgio Szegö (the editor) during the reviewing process is also acknowledged.

\section{Appendix A. Ex ante optimal risk sharing problem}

$\forall \widetilde{R}$ and $\tilde{t}$ the following problem is solved:

$$
\max _{c_{1}, c_{2}, K}\left\{t U\left(c_{1}\right)+\left(\begin{array}{ll}
1 & t
\end{array}\right) U\left(c_{2}\right)\right\}
$$


s.t.

$$
\begin{aligned}
& t c_{1} \leqslant K L, \\
& (1 \quad t) c_{2} \leqslant(1 \quad K) R, \\
& c_{1} \leqslant c_{2} .
\end{aligned}
$$

The first order conditions to this problem are the following ones:

$$
\begin{aligned}
& \frac{\partial L}{\partial c_{1}} \quad\left(c_{1}+1\right)^{-\gamma} t \quad \frac{t}{L} \lambda_{1} \quad \lambda_{2} \quad 0, \\
& \frac{\partial L}{\partial c_{2}} \quad\left(c_{2}+1\right)^{-\gamma}(1 \quad t) \quad \frac{(1 t)}{R} \lambda_{1}+\lambda_{2} \quad 0, \\
& \frac{\partial L}{\partial \lambda_{1}} \quad 1 \quad t \frac{c_{1}}{L} \quad(1 \quad t) \frac{c_{2}}{R} \quad 0, \\
& \frac{\partial L}{\partial \lambda_{2}} \quad c_{2} \quad c_{1} \geqslant 0 .
\end{aligned}
$$

The incentive constraint is never binding $\left(\begin{array}{ll}\lambda_{2} & 0\end{array}\right)$.

From (A.3a) and (A.3b):

$$
c_{2}^{*} \quad\left(\frac{R}{L}\right)^{1 / \gamma}\left(c_{1}^{*}+1\right) \quad 1 .
$$

Substituting the value of $c_{2}^{*}$ in $(\mathrm{A} .3 \mathrm{c})$ :

$$
c_{1}^{*} \frac{1+\frac{1-t}{R}\left[1\left(\frac{R}{L}\right)^{1 / \gamma}\right]}{\frac{(1 t)}{L^{1 / \gamma}} R^{(1-\gamma) / \gamma}+\frac{t}{L}} .
$$

Substituting the values of $c_{1}^{*}$ and $c_{2}^{*}$ in (A.3d) it can be shown that this case is satisfied as long as $\widetilde{R} \geqslant L$.

The incentive constraint is binding $\left(\lambda_{2}>0\right)$.

From (A.3d):

$$
c_{1}^{*} \quad c_{2}^{*} \text {. }
$$

Substituting (A.6) in (A.3c):

$$
c_{1}^{*} \quad c_{2}^{*} \frac{R L}{t R+\left(\begin{array}{ll}
1 & t
\end{array}\right) L} .
$$

Similarly, it can be shown that this case is satisfied as long as $\widetilde{R}<L$. 
The expected utility achieved would be:

(a) If $L<R_{1}$ :

$$
\begin{aligned}
& U^{*} \quad r_{1}\left\{(1 \quad p)\left[t_{1} A\left(t_{1}, R_{\mathrm{h}}\right)+\left(\begin{array}{ll}
1 & t_{1}
\end{array}\right) B\left(t_{1}, R_{\mathrm{h}}\right)\right]+p\left[t_{1} A\left(t_{1}, R_{1}\right)\right.\right. \\
& \left.\left.+\left(\begin{array}{ll}
1 & t_{1}
\end{array}\right) B\left(t_{1}, R_{1}\right)\right]\right\}+r_{2}\left\{\left(\begin{array}{ll}
1 & p
\end{array}\right)\left[t_{2} A\left(t_{2}, R_{\mathrm{h}}\right)+\left(\begin{array}{ll}
1 & t_{2}
\end{array}\right) B\left(t_{2}, R_{\mathrm{h}}\right)\right]\right. \\
& \left.+p\left[t_{2} A\left(t_{2}, R_{1}\right)+\left(\begin{array}{ll}
1 & t_{2}
\end{array}\right) B\left(t_{2}, R_{1}\right)\right]\right\}
\end{aligned}
$$

where

$$
A(R, t) \frac{\left\{\frac{1+\frac{(1 t)}{R}\left[1\left(\frac{R}{L}\right)^{1 / \gamma}\right]}{\frac{(1 t)}{L^{1 / \gamma}} R^{(1-\gamma) / \gamma}+\frac{t}{L}}+1\right\}^{1-\gamma}}{1 \gamma} ;
$$

$$
B(R, t) \frac{\left[\left(\frac{R}{L}\right)^{1 / \gamma}\left\{\frac{1+\frac{(1 t)}{R}\left[1\left(\frac{R}{L}\right)^{1 / \gamma}\right]}{\frac{(1 t)}{L^{1 / \gamma}} R^{(1-\gamma) / \gamma}+\frac{t}{L}}+1\right\}\right]^{1-\gamma}}{1 \gamma} .
$$

(b) If $R_{1}<L<R_{\mathrm{h}}$ :

$$
\begin{array}{rl}
U^{*} & p\left[r_{1} C\left(t_{1}, R_{1}\right)+r_{2} C\left(t_{2}, R_{1}\right)\right]+r_{1}(1 \quad p)\left[t_{1} A\left(t_{1}, R_{\mathrm{h}}\right)+\left(\begin{array}{ll}
1 & t_{1}
\end{array}\right) B\left(t_{1}, R_{\mathrm{h}}\right)\right] \\
& +r_{2}\left(\begin{array}{ll}
1 & p
\end{array}\right)\left[\begin{array}{ll}
t_{1} A\left(t_{2}, R_{\mathrm{h}}\right)+\left(\begin{array}{ll}
1 & t_{2}
\end{array}\right) B\left(t_{2}, R_{\mathrm{h}}\right)
\end{array}\right]
\end{array}
$$

where

$$
C(t, R) \quad \frac{\left[\frac{R L}{t R+(1 t) L}+1\right]^{1-\gamma}}{1 \gamma} .
$$

\section{Appendix B. The demand deposit contract with runs}

The problem to be solved is

$$
\begin{aligned}
\max _{\substack{c_{1}, c_{2 \mathrm{~h}}, c_{21}^{t_{1}}, c_{2 \mathrm{~h}}^{t_{2}}, c_{21}^{t_{2}}\\
}} & r_{1}\left(t_{1} U\left(c_{1}\right)+\left(\begin{array}{ll}
1 & t_{1}
\end{array}\right)\left[\left(\begin{array}{ll}
1 & p
\end{array}\right) U\left(c_{2 \mathrm{~h}}^{t_{1}}\right)+p U\left(c_{21}^{t_{1}}\right)\right]\right) \\
& \left.+r_{2}\left(t_{2} U\left(c_{1}\right)+\left(\begin{array}{ll}
1 & t_{2}
\end{array}\right)\left[\left(\begin{array}{ll}
1 & p
\end{array}\right) U\left(c_{2 \mathrm{~h}}^{t_{2}}\right)+p U\left(c_{21}^{t_{2}}\right)\right]\right)\right\}
\end{aligned}
$$

s.t.

$$
\begin{aligned}
& t_{1} \frac{c_{1}}{L}+\left(\begin{array}{llll}
1 & t_{1}
\end{array}\right) \frac{c_{2 \mathrm{~h}}^{t_{1}}}{R_{\mathrm{h}}} \quad 1, \quad t_{1} \frac{c_{1}}{L}+\left(\begin{array}{lll}
1 & t_{1}
\end{array}\right) \frac{c_{21}^{t_{1}}}{R_{1}} \quad 1, \\
& t_{2} \frac{c_{1}}{L}+\left(\begin{array}{llll}
1 & t_{2}
\end{array}\right) \frac{c_{2 \mathrm{~h}}^{t_{2}}}{R_{\mathrm{h}}} \quad 1, \quad t_{2} \frac{c_{1}}{L}+\left(\begin{array}{lll}
1 & t_{2}
\end{array}\right) \frac{c_{21}^{t_{2}}}{R_{1}} \quad 1,
\end{aligned}
$$

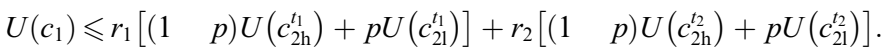


From the first and second budget constraints it is obtained that $c_{21}^{t_{1}} \quad c_{2 \mathrm{~h}}^{t_{1}}\left(R_{1} / R_{\mathrm{h}}\right)$. Similarly, from the third and fourth one $c_{21}^{t_{2}} \quad c_{2 \mathrm{~h}}^{t_{2}}\left(R_{1} / R_{\mathrm{h}}\right)$. Substituting the values of $c_{21}^{t_{1}}$ and $c_{21}^{t_{2}}$ in the above problem, it may be formulated again as follows:

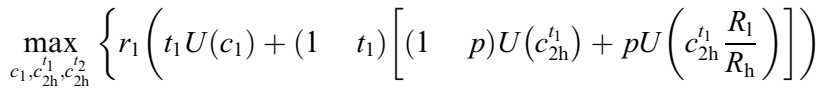

$$
\begin{aligned}
& \left.+r_{2}\left(t_{2} U\left(c_{1}\right)+\left(\begin{array}{ll}
1 & t_{2}
\end{array}\right)\left[\left(\begin{array}{ll}
1 & p
\end{array}\right) U\left(c_{2 \mathrm{~h}}^{t_{2}}\right)+p U\left(c_{2 \mathrm{~h}}^{t_{2}} \frac{R_{1}}{R_{\mathrm{h}}}\right)\right]\right)\right\}
\end{aligned}
$$

s.t.

$$
\begin{aligned}
& t_{1} \frac{c_{1}}{L}+\left(\begin{array}{lll}
1 & t_{1}
\end{array}\right) \frac{c_{2 \mathrm{~h}}^{t_{1}}}{R_{\mathrm{h}}} \quad 1 ; \quad t_{2} \frac{c_{1}}{L}+\left(\begin{array}{lll}
1 & t_{2}
\end{array}\right) \frac{c_{2 \mathrm{~h}}^{t_{2}}}{R_{\mathrm{h}}} \quad 1,
\end{aligned}
$$

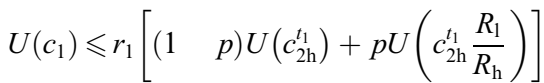

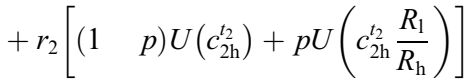

The FOCS are the following ones:

$$
\begin{aligned}
& \frac{\partial L}{\partial c_{1}} \quad\left(c_{1}+1\right)^{-\gamma} t \quad \frac{t_{1}}{L} \lambda_{1} \frac{t_{2}}{L} \lambda_{2} \quad\left(c_{1}+1\right)^{-\gamma} \lambda_{3} \quad 0, \\
& \frac{\partial L}{\partial c_{2 \mathrm{~h}}^{t_{1}}} \quad r_{1}\left[\left(\begin{array}{ll}
1 & \left.p)\left(c_{2 \mathrm{~h}}^{t_{1}}+1\right)^{-\gamma}+p\left(c_{2 \mathrm{~h}}^{t_{1}} \frac{R_{1}}{R_{\mathrm{h}}}+1\right)^{-\gamma}\right]\left[\left(\begin{array}{ll}
1 & t_{1}
\end{array}\right)+\lambda_{3}\right.
\end{array}\right]\right. \\
& \frac{\left(1 \quad t_{1}\right)}{R_{\mathrm{h}}} \lambda_{1} \quad 0, \\
& \frac{\partial L}{\partial c_{2 \mathrm{~h}}^{t_{2}}} \quad r_{2}\left[\left(\begin{array}{ll}
1 & \left.p)\left(c_{2 \mathrm{~h}}^{t_{2}}+1\right)^{-\gamma}+p\left(c_{2 \mathrm{~h}}^{t_{2}} \frac{R_{1}}{R_{\mathrm{h}}}+1\right)^{-\gamma}\right]\left[\begin{array}{ll}
1 & t_{2}
\end{array}\right)+\lambda_{3}
\end{array}\right]\right. \\
& \frac{\left(1 \quad t_{2}\right)}{R_{\mathrm{h}}} \lambda_{2} \quad 0, \\
& \frac{\partial L}{\partial \lambda_{1}} \quad 1 \quad t_{1} \frac{c_{1}}{L} \quad\left(1 \quad t_{1}\right) \frac{c_{2 \mathrm{~h}}^{t_{1}}}{R} \quad 0, \\
& \frac{\partial L}{\partial \lambda_{2}} \quad 1 \quad t_{2} \frac{c_{1}}{L} \quad\left(1 \quad t_{2}\right) \frac{c_{2 \mathrm{~h}}^{t_{2}}}{R} \quad 0,
\end{aligned}
$$

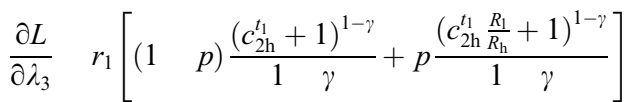

$$
\begin{aligned}
& +r_{2}\left[(1 \quad p) \frac{\left(c_{2 \mathrm{~h}}^{t_{2}}+1\right)^{1-\gamma}}{1 \gamma}+p \frac{\left(c_{2 \mathrm{~h}}^{t_{2}} \frac{R_{1}}{R_{\mathrm{h}}}+1\right)^{1-\gamma}}{1 \gamma}\right] \quad \frac{\left(c_{1}+1\right)^{1-\gamma}}{1 \gamma} \geqslant 0,
\end{aligned}
$$

and where $t \quad r_{1} t_{1}+r_{2} t_{2}$. 
From (B.7d):

$$
c_{2 \mathrm{~h}}^{t_{1} *} \quad \frac{\left(1 \frac{t_{1}}{L} c_{1}^{*}\right) R_{\mathrm{h}}}{1 \quad t_{1}} .
$$

From (B.7e):

$$
c_{2 \mathrm{~h}}^{t_{2} *} \quad \frac{\left(1 \frac{t_{2}}{L} c_{1}^{*}\right) R_{\mathrm{h}}}{1} t_{2},
$$

and the value of $c_{1}^{*}$ is obtained as a solution to one of the following non linear equations.

(i) The incentive constraint is never binding $\left(\begin{array}{ll}\lambda_{3} & 0\end{array}\right)$. In this case the non linear equation is obtained substituting the values of $\lambda_{1}$ from (B.7b) and $\lambda_{2}$ from (B.7c) in (B.7a):

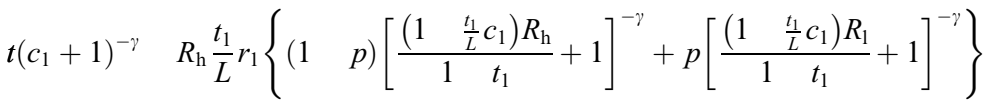

$$
\begin{aligned}
& \left.R_{\mathrm{h}} \frac{t_{2}}{L} r_{2}\left\{\left(\begin{array}{ll}
1 & p
\end{array}\right)\left[\frac{\left(\begin{array}{ll}
1 & \frac{t_{2}}{L} c_{1}
\end{array}\right) R_{\mathrm{h}}}{1}+1\right]_{2}\right]^{-\gamma}+p\left[\frac{\left(\begin{array}{ll}
1 & \frac{t_{2}}{L} c_{1}
\end{array}\right) R_{1}}{1 \frac{t_{2}}{2}}+1\right]^{-\gamma}\right\} 0 .
\end{aligned}
$$

(ii) The incentive constraint is binding $\left(\lambda_{3}>0\right)$. In this case, the non linear equa tion to be solved would be (B.7f) and $c_{2 \mathrm{~h}}^{t_{1}}$ and $c_{2 \mathrm{~h}}^{t_{2}}$ as given in (B.8) and (B.9).

\section{B.1. Suspension of convertibility}

The ex ante expected utility when a suspension of convertibility policy is applied is defined as follows. ${ }^{13}$

If $L<R_{1}$ :

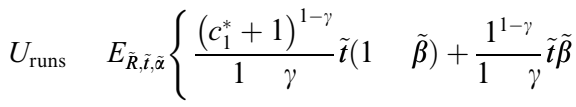

$$
\begin{aligned}
& +\frac{\left(\tilde{x}_{I}+1\right)^{1-\gamma}}{1 \gamma}\left(\begin{array}{lll}
1 & \tilde{t}) \tilde{\alpha}(1 & \tilde{\beta}
\end{array}\right)+\frac{\left(\widetilde{c_{2}}+1\right)^{1-\gamma}}{1 \gamma}\left(\begin{array}{ll}
1 & \tilde{t}
\end{array}\right) \tilde{\alpha} \tilde{\beta} \\
& +\frac{\left(\tilde{x}_{\mathrm{U}}+1\right)^{1-\gamma}}{1 \gamma}\left(\begin{array}{llll}
1 & \tilde{t}
\end{array}\right)(1 \quad \tilde{\alpha})(1 \quad \tilde{\beta}) \\
& \left.+\frac{\left(\widetilde{c_{2}}+1\right)^{1-\gamma}}{1} \gamma\left(\begin{array}{lll}
1 & \tilde{t}
\end{array}\right)\left(\begin{array}{ll}
1 & \tilde{\alpha}
\end{array}\right) \tilde{\beta}\right\} .
\end{aligned}
$$

\footnotetext{
${ }^{13} \widetilde{c_{2}}$ indicates the dependence on the state of nature $(\tilde{\theta})$ and on the amount of type 2 agents rationed in the first period $(\tilde{\beta})$.
} 
If $R_{1}<L<R_{\mathrm{h}}$ :

(a) In states 1, 2, 4 and 5:

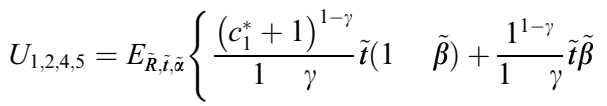

$$
\begin{aligned}
& +\frac{\left(\widetilde{x_{\mathrm{I}}}+1\right)^{1-\gamma}}{1 \gamma}\left(\begin{array}{lll}
1 & \tilde{t}
\end{array}\right) \tilde{\alpha}\left(\begin{array}{ll}
1 & \tilde{\beta}
\end{array}\right)+\frac{\left(\widetilde{c_{2}}+1\right)^{1-\gamma}}{1 \gamma}\left(\begin{array}{ll}
1 & \tilde{t}
\end{array}\right) \tilde{\alpha} \tilde{\beta} \\
& +\frac{\left(\tilde{x}_{U}+1\right)^{1-\gamma}}{1 \gamma}\left(\begin{array}{llll}
1 & \tilde{t}
\end{array}\right)\left(\begin{array}{lll}
1 & \tilde{\alpha}
\end{array}\right)\left(\begin{array}{ll}
1 & \tilde{\beta}
\end{array}\right) \\
& \left.+\frac{\left(\widetilde{c_{2}}+1\right)^{1-\gamma}}{1} \gamma\left(\begin{array}{lll}
1 & \tilde{t})(1 & \tilde{\alpha}
\end{array}\right) \tilde{\beta}\right\}
\end{aligned}
$$

where $\tilde{\beta}=\widetilde{C T_{1}} \quad t_{2} c_{1}^{*} / \widetilde{C T_{1}}$ if $\widetilde{C T_{1}}>t_{2} c_{1}$ and otherwise $\tilde{\beta}=0$.

(b) In states 3 and 6 :

$$
U_{3,6}=\left\{\frac{L}{c_{1}^{*}} \frac{\left(c_{1}^{*}+1\right)^{1-\gamma}}{1 \gamma}+\left(\begin{array}{ll}
1 & \frac{L}{c_{1}^{*}}
\end{array}\right) \frac{1^{1-\gamma}}{1 \gamma}\right\} p q .
$$

So in this case the expected utility with suspension would be: $U_{\text {runs }}=U_{1,2,4,5}+U_{3,6}$.

\section{Appendix C. The demand deposit contract without runs}

The problem to be solved is

$$
\begin{aligned}
& \max _{c_{1}, c_{2 \mathrm{~h}}^{t_{1}}, c_{2 \mathrm{~h}}^{2}}\left\{r _ { 1 } \left(t_{1} U\left(c_{1}\right)+\left(\begin{array}{ll}
1 & t_{1}
\end{array}\right)\left[\left(\begin{array}{ll}
1 & \left.\left.p) U\left(c_{2 \mathrm{~h}}^{t_{1}}\right)+p U\left(c_{2 \mathrm{~h}}^{t_{1}} \frac{R_{1}}{R_{\mathrm{h}}}\right)\right]\right)
\end{array}\right)\right.\right.\right. \\
& \left.+r_{2}\left(t_{2} U\left(c_{1}\right)+\left(\begin{array}{ll}
1 & t_{2}
\end{array}\right)\left[\left(\begin{array}{ll}
1 & p
\end{array}\right) U\left(c_{2 \mathrm{~h}}^{t_{2}}\right)+p U\left(c_{2 \mathrm{~h}}^{t_{2}} \frac{R_{1}}{R_{\mathrm{h}}}\right)\right]\right)\right\}
\end{aligned}
$$

s.t.

$$
\begin{aligned}
& t_{1} \frac{c_{1}}{L}+\left(\begin{array}{ll}
1 & t_{1}
\end{array}\right) \frac{c_{2 \mathrm{~h}}^{t_{1}}}{R_{\mathrm{h}}}=1, \quad t_{2} \frac{c_{1}}{L}+\left(\begin{array}{ll}
1 & t_{2}
\end{array}\right) \frac{c_{2 \mathrm{~h}}^{t_{2}}}{R_{\mathrm{h}}}=1, \\
& U\left(c_{1}\right) \leqslant r_{1} U\left(c_{2 \mathrm{~h}}^{t_{1}} \frac{R_{1}}{R_{\mathrm{h}}}\right)+r_{2} U\left(\begin{array}{l}
c_{2 \mathrm{~h}}^{t_{2}} \frac{R_{1}}{R_{\mathrm{h}}}
\end{array}\right) .
\end{aligned}
$$

The FOCS are the following ones:

$$
\begin{aligned}
& \frac{\partial L}{\partial c_{1}}=\left(c_{1}+1\right)^{-\gamma} t \quad \frac{t_{1}}{L} \lambda_{1} \quad \frac{t_{2}}{L} \lambda_{2} \quad\left(c_{1}+1\right)^{-\gamma} \lambda_{3}=0, \\
& \frac{\partial L}{\partial c_{2 \mathrm{~h}}^{t_{1}}}=r_{1}\left(1 \quad t_{1}\right)\left[\left(\begin{array}{ll}
1 & p
\end{array}\right)\left(c_{2 \mathrm{~h}}^{t_{1}}+1\right)^{-\gamma}+p\left(c_{2 \mathrm{~h}}^{t_{1}} \frac{R_{1}}{R_{\mathrm{h}}}+1\right)^{-\gamma}\right] \quad \frac{\left(1 \quad t_{1}\right.}{R_{\mathrm{h}}} \lambda_{1} \\
& +r_{1}\left(c_{2 \mathrm{~h}}^{t_{1}} \frac{R_{1}}{R_{\mathrm{h}}}+1\right)^{-\gamma} \lambda_{3}=0,
\end{aligned}
$$




$$
\begin{aligned}
& \frac{\partial L}{\partial c_{2 \mathrm{~h}}^{t_{2}}}=r_{2}\left(\begin{array}{ll}
1 & t_{2}
\end{array}\right)\left[\left(\begin{array}{ll}
1 & p
\end{array}\right)\left(c_{2 \mathrm{~h}}^{t_{2}}+1\right)^{-\gamma}+p\left(c_{2 \mathrm{~h}}^{t_{2}} \frac{R_{1}}{R_{\mathrm{h}}}+1\right)^{-\gamma}\right] \quad \frac{\left(1 \quad t_{2}\right.}{R_{\mathrm{h}}} \lambda_{2} \\
& +r_{2}\left(c_{2 \mathrm{~h}}^{t_{2}} \frac{R_{1}}{R_{\mathrm{h}}}+1\right)^{-\gamma} \lambda_{3}=0 \\
& \frac{\partial L}{\partial \lambda_{1}}=1 \quad t_{1} \frac{c_{1}}{L} \quad\left(1 \quad t_{1}\right) \frac{c_{2 \mathrm{~h}}^{t_{1}}}{R_{\mathrm{h}}}=0, \\
& \frac{\partial L}{\partial \lambda_{2}}=1 \quad t_{2} \frac{c_{1}}{L} \quad\left(1 \quad t_{2}\right) \frac{c_{2 \mathrm{~h}}^{t_{2}}}{R_{\mathrm{h}}}=0, \\
& \frac{\partial L}{\partial \lambda_{3}}=r_{1} \frac{\left(c_{2 \mathrm{~h}}^{t_{1}} \frac{R_{1}}{R_{\mathrm{h}}}+1\right)^{1-\gamma}}{1 \gamma}+r_{2} \frac{\left(c_{2 \mathrm{~h}}^{t_{2}} \frac{R_{1}}{R_{\mathrm{h}}}+1\right)^{1-\gamma}}{1 \gamma} \quad \frac{\left(c_{1}+1\right)^{1-\gamma}}{1 \gamma} \geqslant 0,
\end{aligned}
$$

and where $t=r_{1} t_{1}+r_{2} t_{2}$.

From (C.4d):

$$
c_{2 \mathrm{~h}}^{t_{1} *}=\frac{\left(1 \quad \frac{t_{1}}{L} c_{1}^{*}\right) R_{\mathrm{h}}}{1 \quad t_{1}}
$$

From (C.4e):

$$
c_{2 \mathrm{~h}}^{t_{2} *}=\frac{\left(1 \frac{t_{2}}{L} c_{1}^{*}\right) R_{\mathrm{h}}}{1 \quad t_{2}}
$$

and the value of $c_{1}^{*}$ is obtained as a solution to the non linear Eq.(C.4f) where $c_{2 \mathrm{~h}}^{t_{1}}$ and $c_{2 \mathrm{~h}}^{t_{2}}$ are those given in (C.5) and (C.6).

Finally, the expected utility achieved is

$$
\begin{aligned}
& U_{\text {no runs }} \quad r_{1}\left\{t_{1} \frac{\left(c_{1}^{*}+1\right)^{1} \gamma}{1 \gamma}+\left(\begin{array}{ll}
1 & t_{1}
\end{array}\right)\left[\left(\begin{array}{ll}
1 & p
\end{array}\right) \frac{\left(c_{2 \mathrm{~h}}^{t_{1} *}+1\right)^{1} \gamma}{1 \gamma}+p \frac{\left(c_{2 \mathrm{~h}}^{t_{1} * \frac{R_{1}}{R_{\mathrm{h}}}}+1\right)^{1} \gamma}{1 \gamma}\right]\right\} \\
& +r_{2}\left\{t_{2} \frac{\left(c_{1}^{*}+1\right)^{1} \gamma}{1 \gamma}+\left(\begin{array}{ll}
1 & t_{2}
\end{array}\right)\left[\left(\begin{array}{ll}
1 & p
\end{array}\right) \frac{\left(c_{2 \mathrm{~h}}^{t_{2} *}+1\right)^{1} \gamma}{1 \gamma}+p \frac{\left(c_{2 \mathrm{~h}}^{t_{2} * \frac{R_{1}}{R_{\mathrm{h}}}}+1\right)^{1} \gamma}{1 \gamma}\right]\right\} \text {. }
\end{aligned}
$$

\section{References}

Allen, F., Gale, D., 1998. Optimal financial crises. Journal of Finance 53, 12451284.

Alonso, I., 1996. On avoiding bank runs. Journal of Monetary Economics 37, 7387.

Bhattacharya, S., Gale, D., 1987. Preference shocks. In: Barnett, W.A., Singletons, K.J. (Eds.), Liquidity and Central Bank Policy, New Approaches to Monetary Economics. Cambridge University Press, Cambridge, pp. 6988.

Bryant, J., 1980. A model of reserves, bank runs and deposit insurance. Journal of Banking and Finance 4, 335344.

Champ, B., Smith, B., Williamson, S., 1996. Currency elasticity and banking panics: Theory and evidence. Canadian Journal of Economics 29, 828864. 
Chari, V., Jagannathan, R., 1988. Banking panics, information and rational expectations equilibrium. Journal of Finance 43 (3), 749761.

Diamond, D., Dybvig, P., 1983. Bank runs, deposit insurance and liquidity. Journal of Political Economy 91 (3), 401419.

Gorton, G., 1988. Banking panics and business cycles. Oxford University Press, Oxford.

Hazlett, D., 1997. Deposit insurance and regulation in a Diamond Dybvig banking model with a risky technology. Economic Theory 9, 453470.

Hellwig, M., 1994. Liquidity provision, banking and the allocation of interest rate risk. European Economic Review 38, 13631389.

Jacklin, C., Bhattacharya, S., 1988. Distinguishing panics and information based bank runs: Welfare and policy implications. Journal of Political Economy 96, 568592.

Lin, P., 1996. Banking incentive constraints and demand deposit contracts with non-linear returns. Economic Theory 8, 2739.

Lindgren, C., Garcia, G., Saal, M., 1996. Bank soundness and macroeconomic policy. International Monetary Fund, Washington, DC.

Mishkin, F., 1995. The Economics of Money, Banking and Financial Markets. Harper Collins College Publishers.

Park, S., 1991. Bank failure contagion in historical perspective. Journal of Monetary Economics 28, 271 286.

Postlewaite, A., Vives, X., 1987. Bank runs as an equilibrium phenomenon. Journal of Political Economy 95, 485491.

Wallace, N., 1988. Another attempt to explain an illiquid banking system: The Diamond Dybvig model with sequential service taken seriously. Quarterly Review of the Federal Reserve Bank of Minneapolis, 316. 